\title{
Projecting climate change impacts both on rice quality and yield in Japan
}

\author{
Masashi OKADA*, Toshichika IIZUMI**, Yousay HAYASHI*, \\ and Masayuki YoKOZAWA**, $\dagger$ \\ $\left(\begin{array}{c}\text { *Graduate School of Life and Environmental Sciences, University of Tsukuba, } \\ \text { 1-1-1 Tennodai, Tsukuba, Ibaraki, 305-8572, Japan } \\ \text { **Agro-Meteorology Division, National Institute for Agro-Environmental Sciences, } \\ \text { 3-1-3 Kannondai, Tsukuba, Ibaraki, 305-8604, Japan }\end{array}\right.$
}

\begin{abstract}
This study examined the impacts of climate change both on rice quality and yield using a climatologically empirical rice quality model together with a process-based rice growth model. The target area is Kyushu in the western part of Japan, where the decline in rice quality already occurs at the present time. After confirming the model reproducibility, we made simulations to project the changes of rice quality under climate change scenarios. All the projections suggested that the rice quality would significantly deteriorate. We analyzed the results by distinguishing the direct and indirect effects of climate based on simulations with changing weather data. It suggested that the indirect effect induced by the shift of the grain-filling period is relatively larger than the direct effect by temperature rise. We also examined the effects of adaptation measure shifting the date of transplanting on rice quality and yield. It is shown that rice quality is more sensitive to the shifting transplanting date than rice yield; consequently, shifting the transplanting date later might be an appropriate measure for the adaptation to climate change.
\end{abstract}

Key words: Adaptation, Quality, Sensitivity, Trade-off, Yield.

\section{Introduction}

It is now accepted that increased atmospheric concentrations of greenhouse gases are the main cause of the ongoing climate change and that these changes are expected to have serious effects on many social sectors (e.g., agriculture, forestry, and energy consumptions). Specifically, since agricultural practices are climate-dependent and yields vary from year to year depending on climate variability, the agricultural sector is particularly exposed to the risk of climate change.

Actually, rice production, the most important staple crop in Asia, has frequently suffered from the extreme weather events such as high temperature stress, cold damage, drought and flooding, which cause quite a large inter-annual variability in regional rice production

Received; July 1, 2011.

Accepted; September 29, 2011.

†Corresponding Author: myokoz@affrc.go.jp (e.g., Rosenzweig and Hillel, 2008; Krishnan et al., 2011). Due to the increasing extreme climate events in recent decades under the ongoing climate change, the risk of crop production to climate variability and change has increasingly been of concern (e.g., Lobell et al., 2008; Tao et al., 2006, 2008, 2009; Yokozawa et al., 2009; Iizumi et al., 2009; Challinor, 2011).

In Japan, the temperature increases have already been influencing rice quality. Actually, the percentage of the first-grade rice kernel showed a declining trend in the western part of Japan. The further climate change would affect rice quality as well as the yield eventually. Since decline in rice quality will bring about the reduction in farmer's income, estimating the changes in rice quality and yield is needed to project the future aspects of the food supply system under climate change. However, few studies have been conducted to assess future climate change impacts both on rice quality and yield, whereas Kawatsu et 
al. (2007) examined the relationship among the past climate and them. In addition, the projection studies of future climate change impacts on rice quality have been done based mainly on field experimental results (Nagahata et al., 2006; Nakagawa et al., 2008). Then, there has been a large gap between the spatial scales at which climate change projections and field experiments are conducted. To project the climate change impacts with the uncertainty, we should stock the knowledge on the impacts at present and in the future on a large geographical domain. It can also provide us valuable information for seeking appropriate cultivation and management.

In this study, we aim to project the future climate change impacts on both rice quality and the yield using the published models. Evaluating rice quality is based on a climatologically empirical model (Okada et al., 2011), which statistically account for the effects of minimum temperature and solar radiation after heading on the formation of chalky grain. For evaluating rice yield, we used a process-based rice growth model (Iizumi et al., 2009). The information on the grainfilling period from heading to maturity is passed from the rice growth model to the rice quality model. We also examined the adaptation measure shifting planting date to evaluate the impacts of climate change both on rice quality and yield.

\section{Data and Models}

\subsection{Datasets}

The Japan's Agricultural Products Inspection Act classifies harvested rice grains into four grades: first grade, second grade, third grade, and irregular. The classification is conducted based on an inspection of the quality in appearance of grains, i.e. the proportions of rice grain within a given size class and with certain color characteristics. Although there are several types of the decline in rice quality in appearance, the major criterion for assigning the rice quality in appearance to lower grades is the percentage of chalky grains (e.g., milky white kernel, ventral white kernel, white-core kernel, white-back kernel, and basal white kernel). Chalky grains are immature and the entire endosperm has a chalky texture, whereas refined whole grains are translucent in appearance (Tashiro and Wardlaw, 1991). In this study, we assumed that the increase in the percentage of chalky grain mainly induces the decline in the percentage of first-grade rice.

We here used the data on the percentage of first-grade rice averaged over a prefecture as an index of rice quality in appearance (hereafter, we abbreviate it to 'rice quality'). The rice quality data for seven prefectures in Kyushu (Fig. 1) for 29 years from 1979 through 2007 were collected from the agricultural statistics published by the Ministry of Agriculture, Forestry, and Fisheries, Japan (MAFF, 2010a) for calibrating and validating a rice quality model.

We also used the data on heading date and yield at a prefecture scale during a period of 1979-2007 (MAFF, 2010b) for calibrating and validating a rice growth model. In addition, information on typhoon tracks and the damage due to strong wind and flood were obtained from the Crop Statistics (MAFF, 2010b) to exclude the data of the years when typhoons severely damaged rice production in this study area, i.e. seven prefectures. For example, in Fukuoka prefecture, the data of four years $(1991,1993,2004$, and 2006) out of the whole data of 29 years were excluded from the analyses. This data exclusion is needed to statistically model the direct relationship between meteorological factors and rice quality and yield.

Daily weather data for daily maximum and minimum temperature and daily total radiation from 1979 through 2007 were retrieved from a gridded dataset, called Mesh-AMeDAS, provided by National Institute for Agro-Environmental Science (Seino, 1993). The spatial resolution of the dataset is 30 " by $45^{\prime \prime}$ in latitude and longitude (about $1 \mathrm{~km}$ by $1 \mathrm{~km}$ ). The data on land use with the same resolution was utilized to identify the spatial distribution of paddy field. The daily weather data were averaged over the grids where the ratio of paddy field area in a grid is more than $20 \%$. It is the mean weather data over paddy field at a prefecture.

We retrieved 17 datasets on climate change scenarios in the middle and the end of the 21st century (20462065 and 2081-2100) for daily maximum and minimum temperatures and daily total radiation over Japan from a gridded dataset, called Mesh Climate Change Data of Japan Ver. 2, (Okada et al., 2009a) with a spatial resolution of about $10 \mathrm{~km}$ by $10 \mathrm{~km}$ (Table 1). The datasets were constructed by linear interpolation from the nine (eight) outputs of seven (six) GCMs under the Special Report on Green House effect Gas (GHG) Emission Scenarios (SRES: Nakicenovic et al., 2000), A1B (A2). For only one GCM, CCCma-CGCM3.1, three ensemble members are available, which were generated from different initial conditions. We applied bias correction to each dataset on climate change 


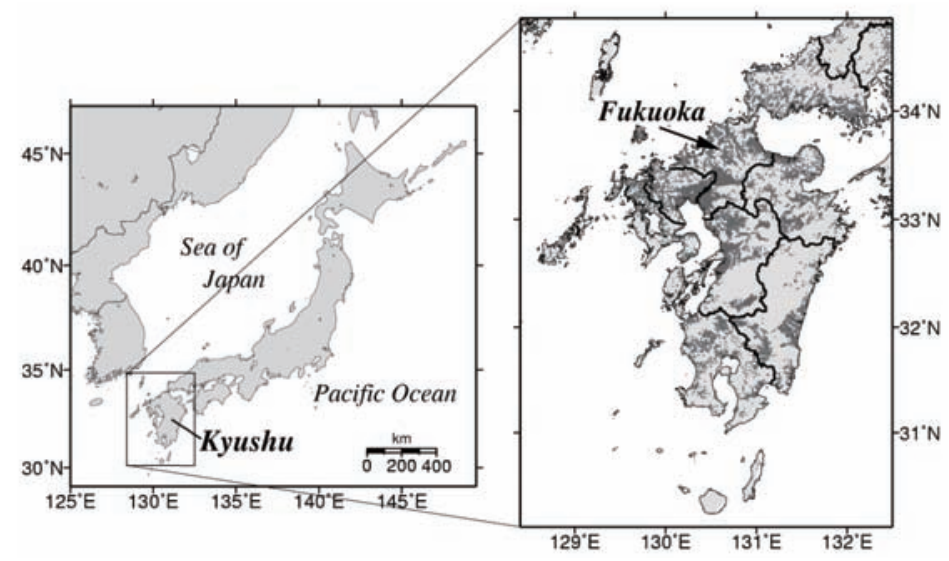

Fig. 1. Map of Japan and Kyushu. Shaded area denotes paddy fields. This figure is redrawn from Okada et al. (2011).

Table 1. CGCMs used in this study

\begin{tabular}{|c|c|c|c|c|c|c|}
\hline \multirow[t]{2}{*}{ Name } & \multirow[t]{2}{*}{ Member (s) } & \multirow[t]{2}{*}{ Abbr. } & \multicolumn{2}{|c|}{$\begin{array}{c}\text { Resolution } \\
\text { (longitude } \times \text { latitude) }\end{array}$} & \multirow[t]{2}{*}{ Country } & \multirow[t]{2}{*}{ General reference } \\
\hline & & & Atmosphere & Ocean & & \\
\hline CCCma-CGCM3.1 & 3 & CGCM3.1 & $3.8^{\circ} \times 3.8^{\circ}$ & $1.9^{\circ} \times 1.9^{\circ}$ & Canada & Flato et al. (2000) \\
\hline $\begin{array}{l}\text { CSIRO-Mk3.0 } \\
\text { CSIRO-Mk3.5 }\end{array}$ & $\begin{array}{l}1 \\
1\end{array}$ & $\begin{array}{l}\text { CSIRO3.0 } \\
\text { CSIRO3.5 }\end{array}$ & $1.9^{\circ} \times 1.9^{\circ}$ & $1.9^{\circ} \times 0.8^{\circ}$ & Australia & Gordon et al. (2002) \\
\hline GFDL-CM2.0 & 1 & GFDL2.0 & $2.5^{\circ} \times 2.0^{\circ}$ & $1.0^{\circ} \times 1.0^{\circ}$ & U.S.A. & Delworth et al. (2006) \\
\hline $\begin{array}{l}\text { MIROC3.2 medres } \\
\text { MIROC3.2 hires }\end{array}$ & $\begin{array}{l}1 \\
1\end{array}$ & $\begin{array}{l}\text { MIROC3.2-med } \\
\text { MIROC3.2-hi }\end{array}$ & $\begin{array}{l}2.8^{\circ} \times 2.8^{\circ} \\
1.1^{\circ} \times 1.1^{\circ}\end{array}$ & $\begin{array}{l}1.4^{\circ} \times 1.4^{\circ} \\
0.3^{\circ} \times 0.2^{\circ}\end{array}$ & Japan & K-1 model developers (2004) \\
\hline MRI-CGCM2.3.2 & 1 & MRI2.3.2 & $2.8^{\circ} \times 2.8^{\circ}$ & $2.5^{\circ} \times 2.0^{\circ}$ & Japan & Yukimoto and Noda (2002) \\
\hline
\end{tabular}

scenario by adjusting the mean and SD (standard deviation) of the 20 years data for the GCM output and the baseline (1981-2000). The detail in bias correction is referred to Iizumi et al. (2010).

To take into account the $\mathrm{CO}_{2}$ fertilization effect on rice growth, we used the data on the past changes of annual atmospheric $\mathrm{CO}_{2}$ concentration provided by the World Data Center for Greenhouse Gases (http://gaw.kishou.go.jp/wdcgg/). For simulating the future changes, we assumed two time change scenarios according to the SRES A1B and A2.

\subsection{Climatological model of rice quality}

From field experimental studies, it has been well known that the poor ripening is enhanced under the weather condition of less solar radiation as well as high temperature during the grain-filling period (e.g., Matsushima and Manaka, 1957). Okada et al. (2009b) also pointed out that the current trend of decreases in rice quality (emergence of chalky grains) in Kyushu is attributed to such weather conditions over large a geographical domain using a multiple regression model. Based on these studies, Okada et al. (2011) proposed a climatologically statistical model for evaluating rice quality (the percentage of first grade rice) on a prefecture level in terms of temperature and solar radiation conditions. Their model is formulated as a logistic function and accounts for the multiple effects of the air temperature and the solar radiation. The details on constructing and validating the non-linear model should be referred to in Okada et al. (2011), we here provide the outline of the model.

The model structure is derived from the following empirical knowledge: rice quality is higher when the temperature after heading is lower than 21 degree Celsius with the less sensitivity to insufficient radiation; rice quality decreases as the temperature rises $(\geq 23$ degree Celsius) and becomes highly sensitive to insufficient solar radiation (Fig. 2). We therefore assumed the relationships between rice quality, temperature and radiation as follows: 


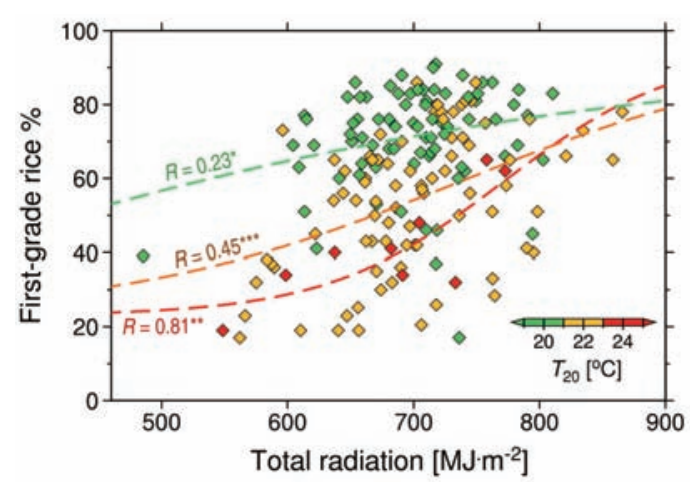

Fig. 2. The response of the percentage of the first grade rice to solar radiation and temperature. Each value represents the mean over prefecture. The total radiation and $T_{20}$ represent the accumulated solar radiation during the period from heading to harvesting and the mean daily minimum temperature during the 20 days after heading, respectively, Plots are colored at three temperature levels. Broken curves indicate the logistic regression fitted to the data at each temperature level annotated with their correlation coefficients $(R)$ and statistical significance (***, $P<0.001$; **, $P<0.01 ; *, P<0.05)$. This figure is redrawn from Okada et al. (2011).

$$
\begin{aligned}
Q= & Q_{\min }\left(T_{\min }\right) \\
& +\frac{Q_{\max }-Q_{\min }\left(T_{\min }\right)}{1+\exp \left[f_{a}\left(T_{\min }\right)\left(S R-f_{b}\left(T_{\min }\right)\right)\right]},
\end{aligned}
$$

where $Q$ is the percentage of the first grade rice (\%) averaged over a prefecture, $Q_{\max }$ and $Q_{\min }\left(T_{\min }\right)$ is the upper and lower limit of $Q$ (\%), respectively, $T_{\min }$ is the mean of daily minimum air temperature $T_{\min , i}$ for $n$ days after heading (degree Celsius), $S R$ is the accumulation of daily solar radiation $S R_{i}$ for $m$ days during the period of the grain-filling stage $\left(\mathrm{MJ} / \mathrm{m}^{2}\right)$.

$$
\begin{aligned}
& T_{\min }=\frac{1}{n} \sum_{i=1}^{n} T_{\min , i}, \\
& S R=\sum_{i=1}^{m} S R_{i} .
\end{aligned}
$$

The number of days, $n$, which represents the length of the period that daily minimum temperature affects the rice quality after heading, is statistically determined by calibrating the rice quality model with the statistical data on the percentage of the first grade rice. The number of days, $m$, which represents the length of the period for the grain-filling stage, is given by the phenology sub-model included in the rice growth model. It is noted that the grain-filling stage is defined as the period from heading to maturity as an output from the model, while it was given as the period from heading to harvest in previous study. Okada et al. (2011) used the rice quality model alone, such that the grain-filling period was given from the statistical data, i.e. the length of the period from heading to harvest. $f_{a}\left(T_{\min }\right)$ is a coefficient representing the sensitivity of $Q$ to $S R$, and $f_{b}\left(T_{\min }\right)$ is the threshold value of $S R$ that gives the halfway value of $Q$ between the upper and lower limits of rice quality, $Q_{\max }$ and $Q_{\min }\left(T_{\min }\right)$.

The variables $Q_{\min }\left(T_{\min }\right), f_{a}\left(T_{\min }\right)$, and $f_{b}\left(T_{\min }\right)$ are assumed to be linear functions of $T_{\min }$.

$$
\begin{aligned}
& Q_{\min }\left(T_{\min }\right)=p_{1} T_{\min }+p_{2}, \\
& f_{a}\left(T_{\min }\right)=p_{3} T_{\min }+p_{4}, \\
& f_{b}\left(T_{\min }\right)=p_{5} T_{\min }+p_{6},
\end{aligned}
$$

where $p_{i}(i=1, \ldots, 6)$ are parameters. The adopted linear functional forms come from not the physiological basis but the statistical simplicity.

In order to estimate seven parameters, we applied Bayesian inference to account for the uncertainty due to the non-climatic factors such as the characteristics of cultivars, cultivation managements and so on. The detailed procedure for estimating parameters using Bayesian inference is referred to in Okada et al. (2009b).

\subsection{Process-based model of rice growth and yield formation}

We used the 'Process-based Regional-scale Rice Yield Simulator with Bayesian Inference' (PRYSBI: Iizumi et al., 2009; Yokozawa et al., 2009) for describing phenological development, growth and yield formation of rice at a prefecture scale. The parameter values of the model are given in a probabilistic manner accounting for the uncertainties in physiological and biophysical responses of rice crop to climatic condition over a large geographical domain, that is associated with the diversity of local weather and crop production aspects (e.g., date of transplanting, cultivar, and management) in a prefecture. The posterior probability distributions of parameters are determined on the basis of the data on heading date and yield on a prefectural scale. The PRYSBI model thereby simulates paddy rice yields in a given prefecture with many sets of the parameter values sampled from the posterior probability distributions and area-averaged 
daily weather data. In that sense, the PRYSBI model is a large-scale crop model and has the advantage in capturing the typical growth and yield of rice crop on a large geographical domain and their uncertainty in contrast to the field-scale crop model, which has a single set of parameter values. Details of the model development, parameter optimization, validation and sensitivity analysis are referred to in Iizumi et al. (2009). In this study, the PRYSBI provides the data on date of heading and the period of the grain-filling stage, from heading to maturity, on a prefecture scale, which are required to the rice quality model.

\section{Results and Discussion}

\subsection{Reproducibility of the models}

Figure 3 depicts an example of the modeled and measured time changes in rice quality and rice yield in Fukuoka prefecture of Kyushu to show the model performance. The modeled results come from the ensemble of simulations with different parameter sets and the gridded weather dataset (Mesh-AMeDAS). Here, the parameter sets were given by sampling the values from the posterior probability distribution for each parameter. The posterior probability distributions reflect the uncertainties attributed to the factors except climate elements such as spatial heterogeneities in cultivation management and cultivars over geographical domain within a prefecture. The differences in results of ensemble of simulations reflect the uncertainty in the parameter estimation, depicted as a shaded area in the figure. The agreement between the modeled and observed values was generally high in terms of the time trend and the year to year variation. The values of the coefficient of determination $R^{2}$ were equal to 0.67 for rice quality and 0.43 for rice yield. The RMSEs (root of mean squared error) were 11.2 (\%) for rice quality and $0.29(\mathrm{t} / \mathrm{ha})$ for rice yield. In addition, the models could reproduce the time changes in rice quality and the yield for all the prefectures except Fukuoka (Iizumi et al., 2009; Okada et al., 2011).

Okada et al. (2011) examined the performance of the rice quality model by evaluating how well the model can predict the rice quality under unprecedented climate conditions taking the year 2010 with an extremely hot summer as an example. They calibrated the model to obtain the parameters without the data from 2010 and simulated the rice quality from the weather data for that year. The model predictions agreed well with the measured data in 2010 for most prefectures (Fig. 6 of Okada et al. (2011)), whereas the model tended to overestimate the rice quality. There was large discrepancy between the model prediction and the measurement in Saga prefecture. Since a hightemperature tolerant cultivar 'Sagabiyori' was rapidly introduced in this area, consequently, no persistence of relevant information on a rapid change in the predominant cultivar in the calibration data explains the inaccurate simulation in this area.

The number of days, $n$ in eqn. (2), which represents the length of the period that the rice quality is sensitive to temperature after heading, can be compared to the results of previous studies. In fact, the mean value of $n$ was estimated to be 30 days by calibrating the rice quality model with the statistics, and this is close to the values reported by Nagato and Ebata (1960), Terashima et al. (2001) and Kondo et al. (2006).

We conducted simulations of rice quality model using the GCM output as a baseline climate during the period 1981 through 2000 instead of the gridded weather dataset to examine the reproducibility. In the
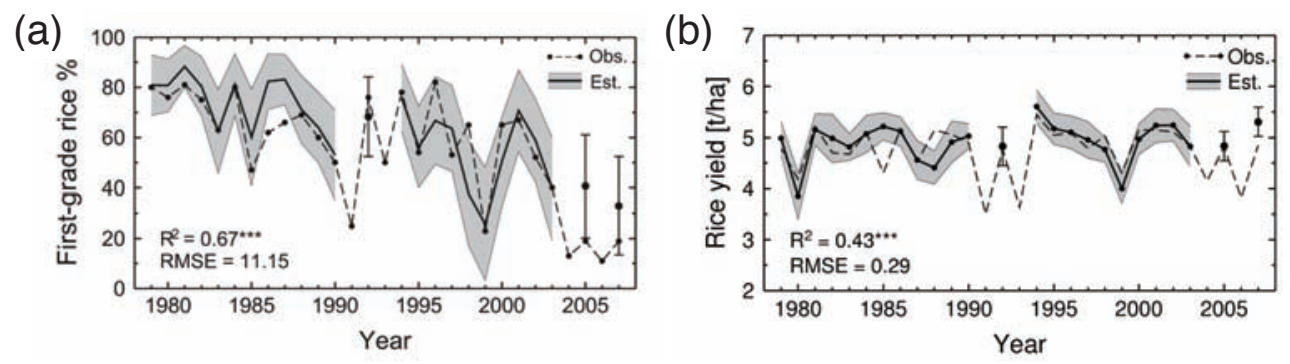

Fig. 3. Time changes of the model estimations and the measured values in the percentage of the first grade rice (a) and the rice yield (b) in Fukuoka prefecture of Kyushu. Bold line represents the mean of ensembles of simulation results with sampling model parameter sets from the posterior distribution of each parameter. Shaded area depicts the SD of the ensembles. The years when typhoon attacked were excluded for the comparison. 
(a)

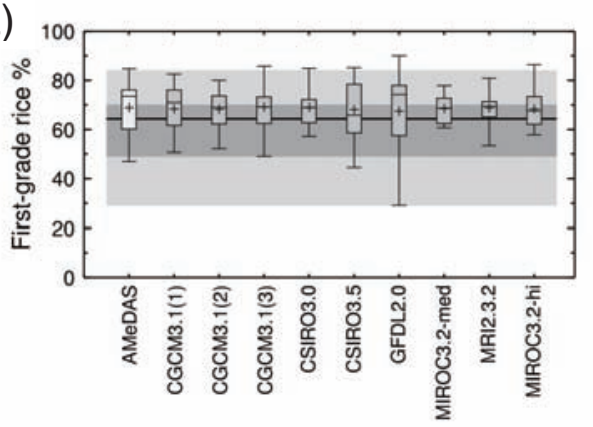

(b)

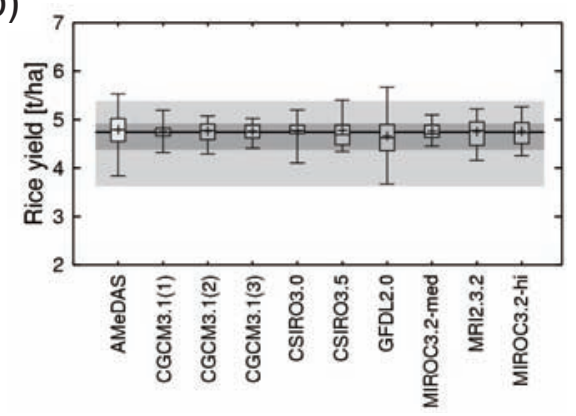

Fig. 4. Comparison of the model estimations with the measured values in the percentage of the first grade rice (a) and the rice yield (b). The names of datasets used for the calculation are listed in the horizontal axis. Box plot denotes the minimum value, the 25 th percentile, the median, the 75 th percentile and the maximum value of ensemble of model results. Cross symbol represents the mean. Bold line represents the mean of the observation. Darker shaded area depicts the range from the 25th percentile to the 75th percentile. Shaded area depicts the range between the minimum and the maximum values. The statistics are calculated from the data averaged over Kyushu during the period of 1981-2000.

simulations for rice quality model, we set the dates of heading and maturity which are output from the rice growth model, PRYSBI. Accounting for the uncertainties, we made 1,000 sets of the dates of heading and maturity from the ensemble of simulations of PRYSBI and 30,000 sets of parameters of rice quality model from the posterior distributions. Subsequently, the simulations of rice quality model were conducted over the cases of 1,000 by 30,000 sets. Figure 4 depicts the comparisons of estimated rice quality and rice yield using different GCM baseline climate data and the gridded weather dataset with the observations. Generally, the ranges of variance of model outputs were smaller than those of observations both for rice quality and rice yield. Specifically, the rice quality model always overestimated the value. Nevertheless, both the rice quality and rice yield models can estimate the mean values during the 20 years well.

\subsection{Impacts of climate change}

The projected changes in rice quality averaged over prefectures in Kyushu induced by climate change are shown in Fig. 5. All the projections suggested that rice quality would significantly decrease, while there are differences among GCMs and GHG emission scenarios. The averaged decrease in rice quality was $-28 \%$ (A1B: $-29 \%$, A2: $-27 \%$ ) over the period 2046 to 2065 and $-41 \%$ (A1B: $-39 \%$, A2: $-44 \%$ ) over the period 2081 to 2100 . Comparing that the average of rice quality over the period 1981 to 2000 except typhoon years was $64 \%$, the projections suggest a large decease in percentage of first grade rice kernels. The lower projections in rice quality came from the simulations using GCMs such as GFDL-CM2.0 and MIROC3.2-hi that project a higher minimum temperature condition during the grain-filling period, from late summer to middle autumn.

Figure 6 shows changes of meteorological conditions, mean daily minimum temperature for $n$ days after heading, i.e. $T_{\min }$ in eqn.(2), and accumulated solar radiation over the grain-filling period, $S R$ in eqn.(3). Here, the number of days after heading, $n$, was determined by calibrating the rice quality model and the period of grain-filling was determined by the projections using the rice growth model with climate change scenarios. For all the scenarios, $T_{\min }$ increases and the period of grain-filling decreases with time resulting in the reduction of $S R$, because the length of the grain-filling period is estimated by a function of daily mean temperature in the rice growth model. Figure 7 depicts time changes in daily minimum temperature under the current climate and the future climate change. The $T_{\min }$ d during each period were 20.3 degree Celsius in 1981-2000, 23.0 degree Celsius in 2046-2065 and 24.6 degree Celsius in 2081-2100. It is reported that the percentage of chalky grains causing the decrease in rice quality sharply increases when the mean daily minimum temperature for 20 days after heading is more than 22.0 degree Celsius (Tsukimori, 2003). The above projections, therefore, imply high temperature stress due to a night-time temperature 


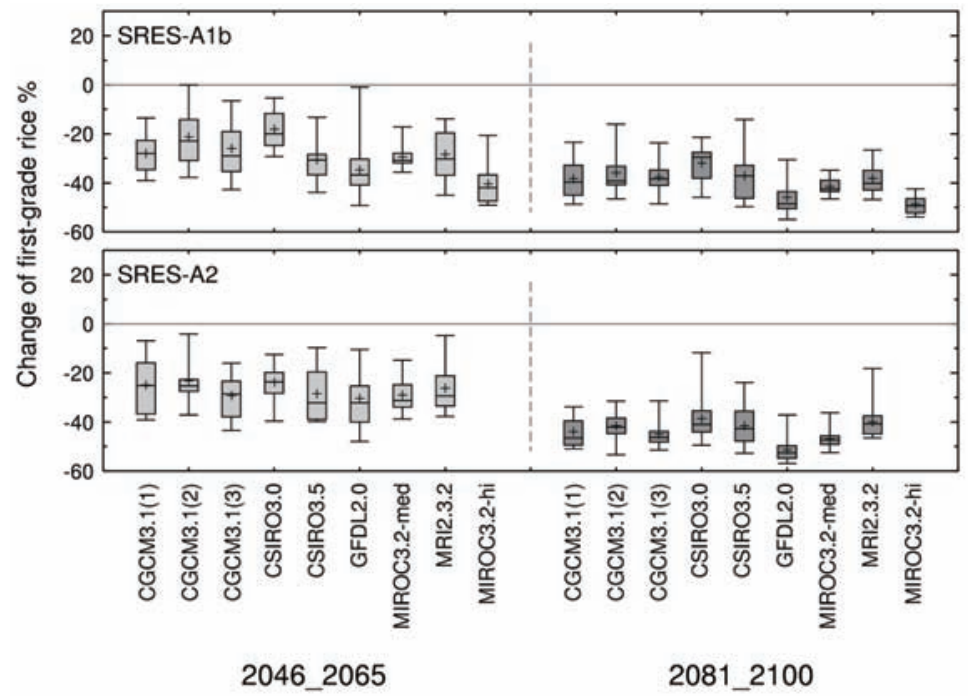

Fig. 5. Changes of the percentage of the first grade rice under climate change: differences from the mean value during the period of 1981-2000. Box plot denotes the same values as in Fig. 4.
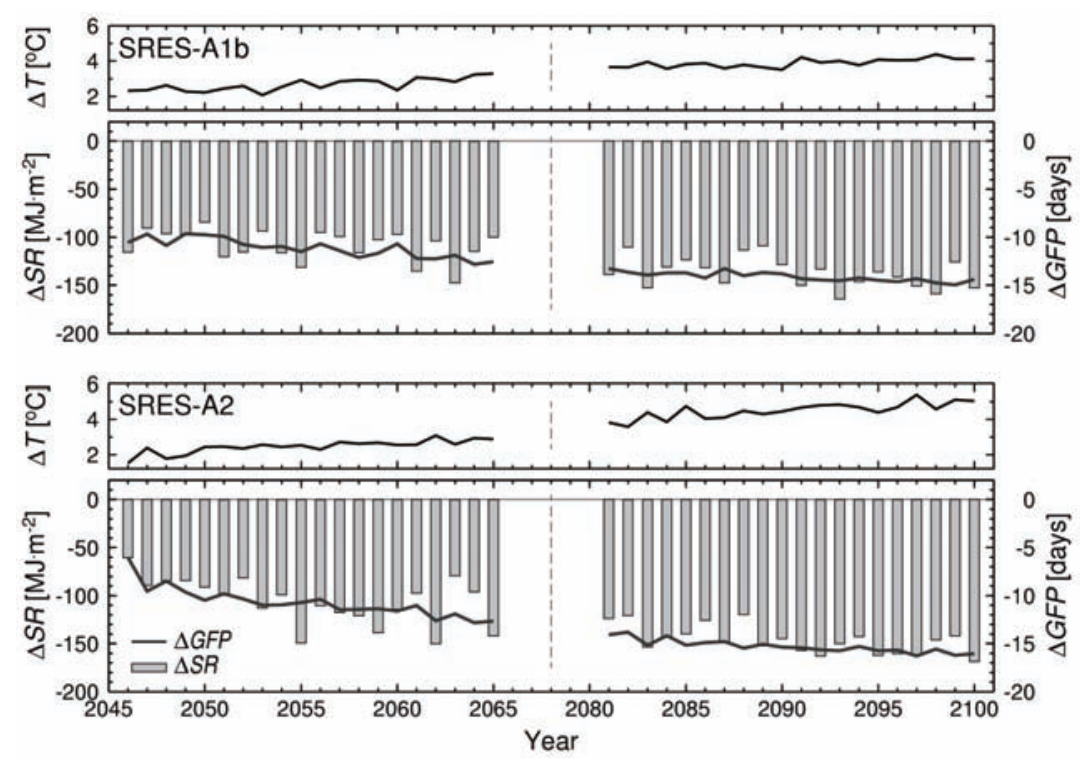

Fig. 6. Time changes of meteorological elements during the period from heading to harvesting under climate change: differences from the average during the period of 1981-2000. The values are mean of outputs of GCMs. $T$ represents the mean daily minimum temperature for $n$ days after heading. The number of days, $n$, is determined by calibrating the rice quality model. GFP is the length of the period from heading to maturity, which is estimated by rice growth model. $S R$ is the accumulated solar radiation during the GFP.

rise would be imposed on rice crops resulting in the decrease in the quality under climate change.

In order to further analyze the effects of mean daily minimum temperature rise on rice crops, we conducted model simulations. For distinguishing the direct effect of climate change from the indirect one of changes in rice growth stage, the simulations were designed as follows: firstly, we made an artificial 


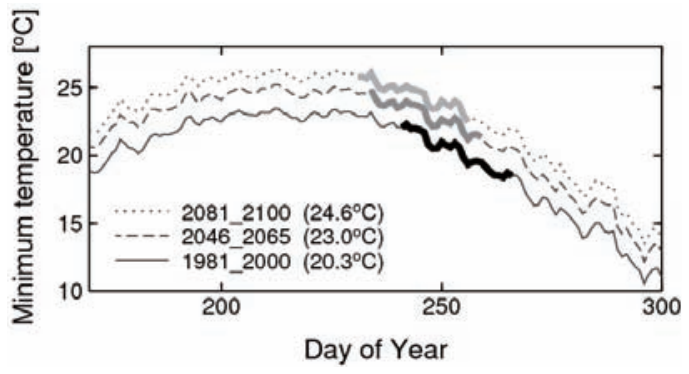

Fig. 7. Time series of daily minimum temperature averaged over Kyushu under the current and future climate. Shaded intervals represent the period that the rice quality is sensitive to minimum temperature, defined as $n$ in eqn. (2). Numerals in parenthesis denote the mean of daily minimum temperature during the period.
Table 2. Simulation design and the rice qual-

\begin{tabular}{llc}
\multicolumn{1}{c}{ ity } & \\
\hline Temperature & Phenology & First-grade rice $\%$ \\
\hline $20 \mathrm{C} 3 \mathrm{M}$ & PHENO & 73.7 \\
$20 \mathrm{C} 3 \mathrm{M}$ & PHENO+2 & 59.4 \\
$20 \mathrm{C} 3 \mathrm{M}+2$ & PHENO & 63.3 \\
$20 \mathrm{C} 3 \mathrm{M}+2$ & PHENO+2 & 45.5 \\
\hline
\end{tabular}

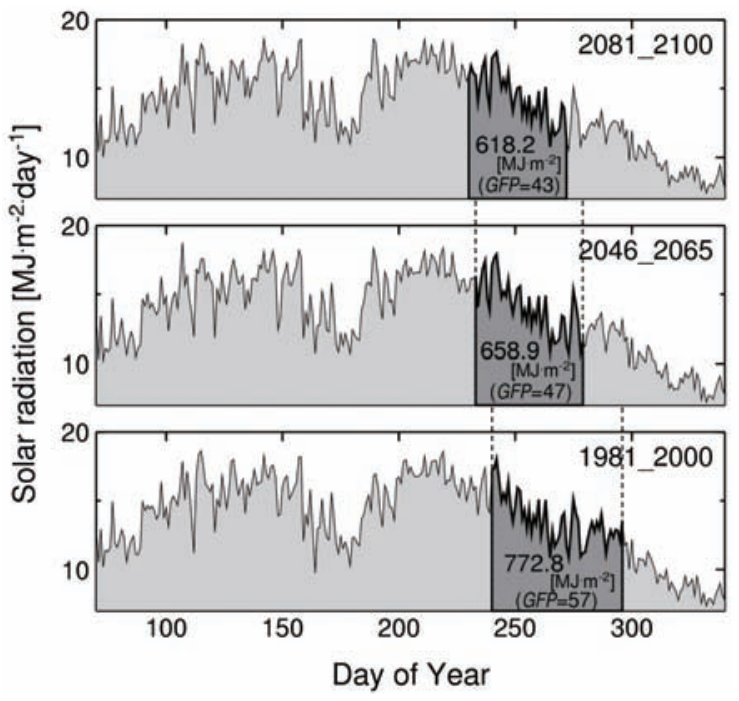

Fig. 8. Time series of daily solar radiation averaged over Kyushu under the current and future climate. Shaded intervals represent the period from heading to maturity, GFP. Numerals denote the accumulated solar radiation during the period.

dataset (hereafter refer to as $20 \mathrm{C} 3 \mathrm{M}+2$ ) that the daily maximum and minimum temperatures were uniformly increased by 2 degree Celsius for each day compared to the baseline temperatures in 1981-2000. Here, we used the baseline temperature from the GCM outputs conducted as an experiment for reproducing the 20th century climate (20C3M); secondly, we calculated the date of heading and the grain-filling period using the rice growth model (PRYSBI) under the two datasets, $20 \mathrm{C} 3 \mathrm{M}$ and $20 \mathrm{C} 3 \mathrm{M}+2$. The datasets on the date of heading and grain-filling period under 20C3M and
$20 \mathrm{C} 3 \mathrm{M}+2$ were referred to as PHENO and PHENO+ 2 , respectively. Then, we calculated the rice quality in the four cases; 20C3M and PHENO, 20C3M and $\mathrm{PHENO}+2,20 \mathrm{C} 3 \mathrm{M}+2$ and $\mathrm{PHENO}$ and $20 \mathrm{C} 3 \mathrm{M}+2$ and $\mathrm{PHENO}+2$. The results summarized in Table 2 suggested that the indirect effect induced by the shift of the grain-filling period is relatively larger than the direct effect by temperature rise.

Solar radiation also affects the change in rice quality directly and indirectly, whereas it is well documented that changes in minimum temperature could affect 

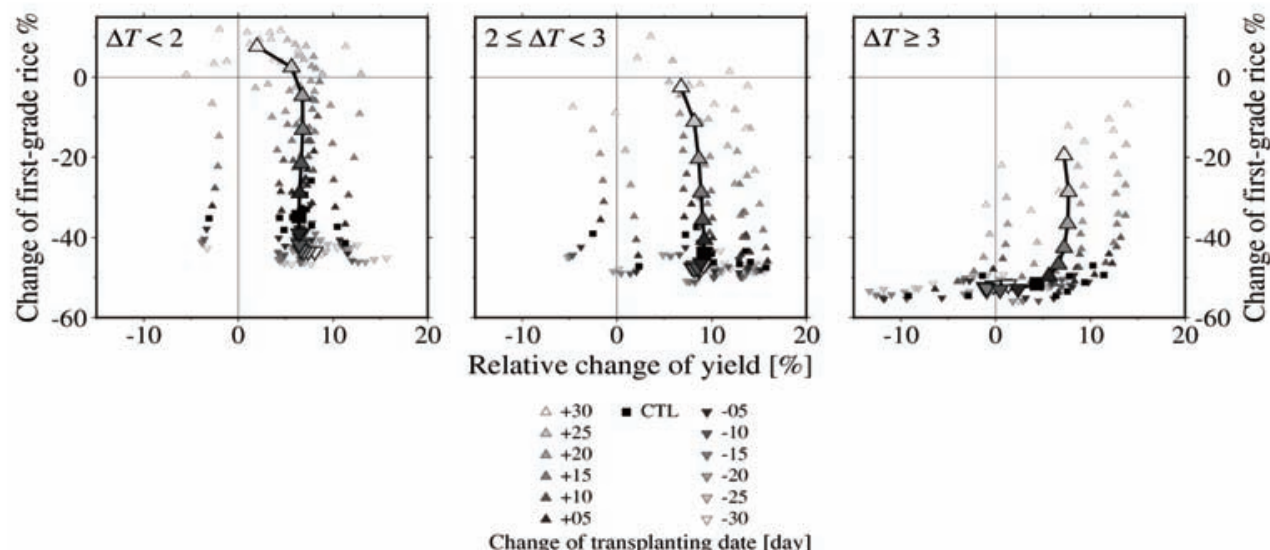

Fig. 9. Effects of shifting the transplanting date on the percentage of the first grade rice and the yield averaged over Kyushu under future climate. Upper triangles represent the simulation results in cases of shifting the transplanting date later compared to the present. Lower triangles represent the simulation results in cases of shifting the transplanting date earlier compared to the present. Large symbols denote the simulation results averaged over the corresponding climate change scenarios (GCM) for each transplanting date. Panels are separately shown with the magnitude of temperature rise during the period from heading to maturity projected by rice growth model and climate change scenarios at the present transplanting condition (CTL).

ripening status, especially rice yield, relatively more than solar radiation (Welch et al., 2010; Krishnan et al., 2011). Figure 8 represents change of solar radiation during the period of grain-filling averaged over Kyushu. Temperature rise enhances the rate of the rice development stage resulting in a shortening of the grain-filling period. Consequently, the carbohydrate demand required for grain-filling cannot be supplied by the assimilation during the shortened period. This may cause the occurrence defects such as chalky grains due to lack of filling starch in the albumen.

We can find the date of heading shift earlier with temperature rises and daily solar radiation increases (Fig. 8). On the other hand, the grain-filling period shortens from 57 days in current climate to 47 days in 2046-2065 and 43 days in 2081-2100 due to temperature rise, resulting in the reduction of accumulated solar radiation during the period of grain-filling. Consequently, there is a trade-off relation between the improvement of available radiation energy per unit time and the shortening of the duration for utilizing the energy. From these projections, we can find that the shortening of the grain-filling period plays a dominant role to determine the rice quality under climate change.

In this model, the length of the grain-filling period is given by the rice growth model as a parameter, $m$, in eqn. (3). The rice growth model tends to estimate the longer period of 57 days as a mean value over the Kyushu area under the current climate, while crop statistics reports the mean period from heading to harvest is about 51 days (MAFF, 2010b). This longer period for grain-filling leads to an overestimation in rice quality (Fig. 4a). Nevertheless, we believe the current model can project the relative changes in rice quality and the yield, because it well describes the responses of the grain-filling period to changes in weather conditions. In addition, to improve the projection, the rice growth model should be calibrated using further observation data such as the timing of maturity beyond the dates of heading and final yield.

It is further noted that the projections on changes in solar radiation by GCMs have large uncertainty and difficulty in the reproduction of the present climate, while most model outputs indicate no significant changes in radiation in summer under climate change (Okada et al., 2009a). The further improvements in predictability of solar radiation of GCM are needed for evaluating the impact of climate change on rice quality as well as rice yield.

\subsection{Adaptation}

In this section, we examine the effects of adaptation measure shifting the date of transplanting on rice quality and yield. Figure 9 depicts simulation results 
of rice quality model and rice growth model (PRYSBI) with changing the date of transplanting under climate change scenarios. The panels were shown separately in terms of the magnitude of temperature rise projected by each climate change scenario.

The decrease in rice quality due to climate change can be reduced by shifting the date of transplanting later compared to the current. This is because shifting the transplanting date induces the shift of the grainfilling period from late summer to early autumn, when the mean temperature decreases and becomes suitable for the grain-filling, while the available daily solar radiation energy decreases. On the other hand, the rice yield is projected to increase under climate change even if the transplanting date remains the same as the current. This result comes from the $\mathrm{CO}_{2}$ fertilization effect rather than high temperature stress on rice yield. In general, shifting the transplanting date earlier can recover the reduction in rice yield irrespective of the degree of temperature rise. In conclusion, rice quality is more sensitive to shifting of the transplanting date than rice yield. Therefore, shifting the transplanting date later might be an appropriate measure for the adaptation to climate change.

\section{Acknowledgments}

We are grateful to Dr. Ryoji Sameshima and two anonymous reviewers for valuable comments on the earlier version of this manuscript. This study was partially supported by the Global Environmental Research Fund (S-4, S-8) of Ministry of the Environment, Japan.

\section{References}

Challinor, A., 2011: Forecasting food. Nat. Clim. Change, 1, 103-104.

Iizumi, T., Yokozawa, M., and Nishimori, M., 2009: Parameter estimation and uncertainty analysis of a large-scale crop model for paddy rice: Application of a Bayesian approach. Agric. For. Meteorol., 149, 333-348.

Iizumi, T., Nishimori, M., Ishigooka, Y., and Yokozawa, M., 2010: Introduction to climate change scenario derived by statistical downscaling. J. Agric. Meteorol., 66, 131-143 (in Japanese with English abstract).

Kawatsu, S., Homma, K., Horie, T., and Shiraiwa, T., 2007: Change of weather condition and its effect on rice production during the past 40 years in Japan.
Jpn. J. Crop Sci., 76, 423-432 (in Japanese with English abstract)

Kondo, M., Morita, S., Nagata, K., Koyama, Y., Ueno, N., Hosoi, J., Ishida, Y., Yamakawa, T., Nakayama, Y., Yoshioka, Y., Ohashi, Y., Iwai, M., Odaira, Y., Nakatsu, S., Katsuba, Z., Hajima, M., Mori, Y., Kimura, H., and M., Sakata, 2006: Effects of air temperature during ripening and grain protein contents on grain chalkiness in rice. Jpn. J. Crop Sci., 75(Extra issue 2), 14-15 (in Japanese)

Krishnan, P., Ramakrishnan, B., Raja Reddy, K., and Reddy, V. R., 2011: High-temperature effects on rice growth, yield, and grain quality. Adv. Agron., 111, 87-206.

Lobell, D. B., Burke, M. B., Tebaldi, C., Mastrandrea, M. D., Falcon, W. P., and Naylor, R., 2008: Prioritizing Climate Change Adaptation Needs for Food Security in 2030. Science, 319, 607-610.

Matsushima, S., and Manaka, T., 1957: Analysis of developmental factors determining yield and yield prediction in lowland rice. Jpn. J. Crop Sci., 25, 203-206 (in Japanese with English summary).

Ministry of Agriculture, Forestry and Fisheries (MAFF), 2010a: Annual Report on Food Control. (Available at http://www.maff.go.jp/j/tokei/kouhyou/ syokuryo_nenkan/index.html on Sep. 1, 2010) (in Japanese).

Ministry of Agriculture, Forestry and Fisheries (MAFF), 2010b: Crop Statistics. (Available at http:// www.maff.go.jp/j/tokei/kouhyou/sakumotu/index. html on Sep. 1, 2010) (in Japanese).

Nagahata, H., Shima, K., and Nakagawa, H., 2006: Modeling and prediction of occurrence of chalky grains in rice 1. A simple model for predicting the occurrence of milky white rice. Jpn. J. Crop Sci., 75(Extra issue 2), 18-19 (in Japanese)

Nagato, K., and Ebata, M., 1960: Effects of temperature in the ripening periods upon the development and qualities of lowland rice kernels. Jpn. J. Crop Sci., 28, 275-278 (in Japanese with English summary).

Nakagawa, H., Nagahata, H., and Tsukaguchi, T., 2008: Modeling and prediction of occurrence of chalky grains in rice 2 . A model to predict the rate of milky white grain using temperature and assimilate supply. Jpn. J. Crop Sci., 77(Extra issue 1), 148-149 (in Japanese).

Nakicenovic, N., Alcamo, J., Davis, G., de Vries, B., Fenhann, J., Gaffin, S., Gregory, K., Grübler, A., Jung, T. Y., Kram, T., La Rovere, E. L., Michaelis, 
L., Mori, S., Morita, T., Pepper, W., Pitcher, H., Price, L., Riahi, K., Roehrl, A., Rogner, H. H., Sankovski, A., Schlesinger, M., Shukla, P., Smith, S., Swart, R., van Rooijen, S., Victor, N., and Dadi, Z., 2000: IPCC Special Report on Emissions Scenarios. Cambridge University Press, Cambridge, U.K., 570 pp.

Okada, M., Iizumi, T., Nishimori, M., and Yokozawa, M., 2009a: Mesh Climate Change Data of Japan Ver. 2 for Climate Change Impact Assessments Under IPCC SRES A1B and A2. J. Agric. Meteorol., 65, 97-109.

Okada, M., Iizumi, T., Hayashi, Y., and Yokozawa, M., 2009b: A climatological analysis on the recent declining trend of rice quality in Japan. J. Agric. Meteorol., 65, 327-337.

Okada, M., Iizumi, T., Hayashi, Y., and Yokozawa, M., 2011: Modeling the multiple effects of temperature and radiation on rice quality. Environ. Res. Lett., 6, 034031.

Rosenzweig, C., and Hillel, D., 2008: Climate variability and the global harvest. Oxford University Press, New York, 259 pp.

Seino, H., 1993: An Estimation of Distribution of Meteorological Elements using GIS and AMeDAS Data. J. Agric. Meteorol., 48, 379-383 (in Japanese).

Tao, F., Yokozawa, M., Xu, Y., Hayashi, Y., and Zhang, Z., 2006: Climate changes and trends in phenology and yields of field crops in China, 1981-2000. Agric. For. Meteorol., 138, 82-92.

Tao, F., Yokozawa, M., Liu, J., and Zhang, Z., 2008: Climate-crop yield relationships at province scales in China and the impacts of recent climate trends. Clim. Res., 38, 83-94.

Tao, F., Yokozawa, M., and Zhang, Z., 2009: Modeling the impacts of weather and climate variability on crop productivity over a large area: A new process-based model development, optimization, and uncertainties analysis. Agric. For. Meteorol., 149, 831-850.

Tashiro, T., and Wardlaw, I. F., 1991: The effect of high temperature on kernel dimensions and the type and occurrence of kernel damage in rice. Aust. J. Agric. Res., 42, 485-496.

Terashima, K., Saito, Y., Sakai, N., Watanabe, T., Ogata, T., and Akita, S., 2001: Effects of high air temperature in summer of 1999 on ripening and grain quality of rice. Jpn. J. Crop Sci., 70, 449-458 (in Japanese with English abstract).

Tsukimori, H., 2003: Effects of high temperature on the rice production and the technical countermeasures in Shimane Prefecture. Jpn. J. Crop Sci., 72(Extra issue 2), 434-439 (in Japanese).

Welch, J. R., Vincent, J. R., Auffhammer, M., Moya, P. F., Dobermann, A., and Dawe, D., 2010: Rice yield in tropical/subtropical Asia exhibit large but opposing sensitivities to minimum and maximum temperatures. PNAS, 107, 14562-14567.

Yokozawa, M., Iizumi, T., and Okada, M., 2009: Large scale projection of climate change impacts on variability in rice yield in Japan. Global Environ. Res., 14, 199-206 (in Japanese). 